\title{
The Experts Views about the Sudanese Secondary Schools English Teacher's Problems and Their Impact on his Performance
}

\author{
Dr. Elrayah Eltahir Adam Khatir \\ Assistant Professor of English, Faculty of Education, University of Bakht-er- Ruda, Sudan- Gassim University KSA
}

\begin{abstract}
In this paper, the author discusses problems in teaching of English language at secondary Level at white Nile sate in Sudan. The study was undertaken to identify the problems of teachers directly as well as students indirectly, regarding the subject. The main objectives of the study were: to identify the problems which affect the performance of secondary school teachers. to investigate the main problems an English teacher faces at Sudanese secondary schools and their impact on his performance. to make recommendations in the light of findings of the study. The participant of the study consists of all English language experts at Sudanese secondary school White Nile state. The sample of the study is 20 experts secondary school English language teachers who were chosen randomly to represent the study. the collected data analysed and interpreted in the light of the objectives. The main conclusions were: teachers face great difficulties with the administration financially, and the field environment as well as colleagues in the departments. On the basis of the conclusions arrived at, recommendations were given. The English language teachers should be provided with special training to overcome the resultant problems. Adequate teaching aids must be provided in schools to facilitate teaching and grasp teachers' attention to teaching.
\end{abstract}

Keywords:

\section{Introduction}

\section{Statement of the Problem:}

Sudanese educators are complained that the English language which is taught in secondary school is far from being satisfactory. It is noticed that a secondary school teacher of English faces many difficulties in the field of teaching due to many reasons which renders the teaching process. This study tries to discuss these problems and suggests solutions and improvements to all these educational difficulties which are significantly challenging

\section{Questions of the Study:}

This study tries to answer the following questions:

- What are the expected difficulties facing English language teaches with the departments' administration?

- Are there difficulties facing English language teachers with colleagues in the department?

- Are there difficulties facing English language teachers in the professional development?

- Are there difficulties facing English language teachers with the curriculum?

- Are there difficulties facing English language teachers in the work environment?

- Are there difficulties facing English language teachers with students?

\section{Significance of the Study}

This study is significant in solving the difficulties and problems that Sudanese teachers of English face in secondary schools white Nile state. It will be useful for supervisors as well as experts who are interested in developing programs for solving English language teachers' problems. It is useful for curriculum planners at white Nile state to solve part of these problems. This study also encourages and motivates teachers and supervisors to face and reduce the obstacles of the teachers' problems.

\section{Limits of the Study}

This study is limited to the Sudanese secondary schools and the teachers of English departments in the Sudan in secondary school year ( 2014-2015) white Nile state.

\section{Literature Review}

\section{Introduction}

English is considered to be the only language of global communication. It is not only seen as a powerful learning tool, a way where people can gain access to information and knowledge from all around the world, but it is also an essential medium in which students can improve positive assessment and performance, achieve and maintain a meaningful relationship with people around the world, increase their cultural understanding and expand their knowledge and world-views. English, furthermore, is the language of international business, trade and professional communication. Wiriyachitra, \& Keyurawong (2002:1).

\section{An English Teacher's Role:}

An English language teacher's major role is not only to enable the students to comprehend what he/she intends to say or teach. In addition, it is said to be the major responsibility of the teacher to understand and comprehend what the students need to learn and practice. Richards (1992: 25).

The roles of an English language teacher in universities are highly confusing in defining the various classifications of a university lecturer's role. Consistent with Braskamp \& Ory's four dimensional classifications (1994: 33), the English language teachers' roles are contained by the parameters of

\section{Volume 4 Issue 12, December 2015}




\section{International Journal of Science and Research (IJSR) \\ ISSN (Online): 2319-7064 \\ Index Copernicus Value (2013): 6.14 | Impact Factor (2014): 5.611}

teaching, research and creativity, practice and professional service and citizenship.

Tamblyn (2000:2) identified ten qualities of a successful teacher in universities, whereas, the first three qualities are the skills of successful teachers as in subject competency, creativity, flexibility in using expertise and motivation. While the remaining seven qualities are related to personality and attitudes such as willingness to take risks and make mistakes, respect for learners, caring, warmth, love and sense of humor, pride in the profession and a willingness to go the extra mile.

\section{Difficulties Facing English Language Teachers:}

TESL-EJ Forum (2000: 33) in - $€$ n the Status of Adjunct Teachers Around the World" pointed out three serious problems that face teachers: decreased level of job security, fewer benefits such as paid vacations, health care, and many more, last but not least; a low pay rate which is considered as the main reason of decreasing the performance rate of English language teachers.

Whereas Brooks (2000:33) in his article classified three primary difficulties that face English language teachers and which have an impact on their performance in their lectures:

1) Finances: where the payment is low compared to other jobs in the society. Moreover, it is admitted that the salary paid to the English language teacher is enough to live on, but at the same time, it is not enough to travel or buy expensive artifacts.

2) Living Conditions: which is also considered as a major problem in the society as a whole.

3) Culture: which is also an affective factor in Tommy's perspective.

In the Middle East, English language teachers go through various difficulties in their career, which will surely affect their performance and achievements in their profession. These difficulties mentioned above may not be shared with other English teachers in other parts of the world. MeSchools (2002: 25).

Professional difficulties facing English language teachers in universities are the most problematic issues for the society and the teachers themselves. These difficulties will be discussed in details as the following:

\section{Difficulties with the Colleagues in the English Department:}

Acker (1999: 49) cited in Wahbi (2000: 28): in his study, he concentrated on the necessity to view the motivations of the English language teacher, the relationship between the teacher and colleagues, and providing an encouraging atmosphere where English language teacher would be capable of cooperating to achieve the common goals of their continuous progression.

While Craft (1997: 33) stated in his study that cooperation and association, which will sometimes be glorified with terms like -ollegiality", partnerships", and eollaboration", will reside very much at the operational and implementation level, for to involve teachers in strategic decision-making might be to threaten the wider mission of the school.

\section{Difficulties with Students:}

Broply (1986:45) cited in Barqawi (1995:21) concluded in his study that a typical English classroom in a university observed under normal conditions that any attempt to develop students' achievement must be based fundamentally on the improvement of tactful teaching behavior. His research concentrates on teacher behaviors and student achievement. It links student achievement to their opportunity to learn the material, and to the degree to which teachers carry the content to them personally through active instruction and move them through the curriculum at a brisk pace.

Jefferson (2001: 49) has found out in his research that English language teachers could encounter students who engage in behaviors that interfere with their education and that of other students in the classroom.

\section{Difficulties with the Administrators of the English Department:}

Researchers have recognized the structure of collegiality to be highly significant to the formation of a more professional culture in universities. The researchers have documented that harms of collaborations are built through the interaction, created by the principal's facilitation of collegial work. It is thought of administrators as sense markers for their universities. Their sensation at leading centers, to a great degree, on their ability to see openly the universities' core functions, to estimate events in light of those functions, and to assess the members of the university's community conduct their work and their relationship in way that serve these core functions Jossy-Bass (2000: 15).

Richard et al (1996: 28) Erklens and Michelle (2001: 43) claimed in their study that teacher's relationship with administrators were influenced by discourses of efficiency and scientific management, which were further supported, especially for female elementary teachers.

\section{Difficulties in Performance Development:}

Acker (1999: 25) cited in ( Wahbi 2000: 31) that English language teachers must take a greater role in improving their own teaching techniques and representing new programs in lectures, and gaining effective management skills. Acker also mentioned that the improvement of teachers concludes more than giving them new methods to teach. Acker added in her research that teachers are required to realize that, what goes on inside the lecture is linked to what goes on outside it.

Likewise, Tamblyn (2000: 41 ) has claimed that there are probable advantages for developing the performance of the English language teacher, which has to be based on the requirements of the departments' policy rather than using a method based on courses selected to meet individual needs. Tamblyn has also concentrated on the significance of decision and progression and such longer term qualities obviously and hardly ever evident in the short-term focus on immediate problems 


\section{International Journal of Science and Research (IJSR) \\ ISSN (Online): 2319-7064}

Index Copernicus Value (2013): 6.14 | Impact Factor (2014): 5.611

\section{Difficulties in Understanding the Text book Curriculum:}

Where as many teachers may not comprehend the curriculum, some others develop the curriculum, define, and reinterpret it as well. The curriculum of any subject, and in English language is considered to be the teachers' thoughts, believes, and goals of teachers and what they should do in their lectures. In some cases, this could create a complexity in the curriculum and some of the members may not understand the curriculum or know how to act based on this curriculum Reys, R. (2001: 28).

\section{Equipments and Capacity Related Difficulties:}

English language teachers face some obstacles among the chronic and branched issues because of the nature of their career. This difficulty does not only include controlling the lecture and the students, or even the presentation of a topic. Still, there is a well known manner of presenting and performing his/her role in teaching in the university. An English language teacher needs some equipments such as optimal teaching aids, or the audio-visuals that might increase the possibility of students to comprehend whatever that might be involved with to learn Hargraves \& Tucker (1999: 12)

\section{Difficulties with the Surrounding Environment:}

Concentrating on the obligation and pressure which affect significantly on the teaching profession, Richard (1996: 32) said that to the never-ending nature of the job: there are always more books to mark, more assignments to prepareand more care to give to one student". The pressure and care ethics can oblige teachers into taking action, in addition to the negative behaviors such as a commitment to unrealistic production, burnout, cynicism, and through over Linacre on the care ethic, a lack of both analysis and proactively.

Word Education Forum (WEF) (2000: 77) abridged in its paper that the working conditions of teachers are closely related to learning conditions for the students.

\section{Methodology}

Researcher used descriptive analytical approach to achieve the goal of the study which is based on the data collection, classification, organization and analysis.

\section{Population}

The population of this study consisted of all English language experts of English language at secondary schools white Nile state in Sudan in the year (2014-2015)

\section{Sample}

The study sample was selected randomly from the population of the study equivalent to 20 expert of English language from white nile state 4 of them over 50 years old the rest are round 40 years old . 9 of them are female and 11 are male experts . 4 of them their experience between 30-25 years of experience the reset their experience less than 21 years

\section{Study Tool}

The study used the interview of four questions (appendix) to collect the data from the sample.

\section{Reliability and Validity}

To ensure instruments reliability and validity the interview exposed to my colleagues in the department and all of them agreed that the interview is comprehensive and on the spot to collect the data of the problems. Then it is distributed to the respondents to collect the data. Logical interpretation of cross check followed to analyse the interview.

\section{Discussion Analysis and Results}

Each axis will be discussed according to the respondents' view points

\section{The difficulties facing English language teachers with the administration:}

14 respondents show the difficulties facing English language teachers with administration. They represent high and average out of twenty respondents they say it lies in the boredom of routine management procedures within the organization. Depriving English language teachers from appreciation and excellence certificates .Absence of the English library of the in schools to an English teacher to follow up. Weak curriculums and educational courses for the English language teachers in in-service. Lack of training courses that enhance the skills of an English language teacher. The lack of interest in providing the English language teacher with new technologies. Congestion of the educational schedule of an English language teacher .Assigning more tasks for the English language teacher in addition to teaching. Routine procedure was considered as one of the problems prevents an English teacher from doing his or her duties perfectly. Management procedures established by the school administration lead to the possibility that teachers commit errors, shortcomings and slow productivity .

\section{The difficulties facing English language teachers with} colleagues in the department:

13 respondents show the impact of the difficulties facing English language teachers with colleagues in the department which was also high average. They agree about these points: there is: poor communication among English language teachers with each other as well as with other colleagues. Non-activation of mutual visits among English language teachers to benefit from exchanging the experiences. No any channels of educational and professional empowerment for English language teachers in order to communicate with each other as magazine workshops etc. many of them say: An English language teacher is incapable of using other skills and experiences of other English language teachers. English language teachers do not respond to their colleagues in changing the educational context. There is no trust among English language teachers in both practical and theoretical sides. Weakness of the spirit of fellowship and communication among teachers of English. English language teachers feel uncomfortable with each other and with other colleagues. 


\section{International Journal of Science and Research (IJSR) \\ ISSN (Online): 2319-7064 \\ Index Copernicus Value (2013): 6.14 | Impact Factor (2014): 5.611}

It is clear that English language teachers who do not participate on social activities in schools and do not interact with their colleagues fail to create communication between teachers and exchange experiences, information and knowledge, in addition to the point that English they do not feel ease and safety when they are dealing with their collogues at schools because of jealousy sometimes. What is said by the respondents This indicates the psychological comfort, reassurances among English language teachers at secondary schools and cooperation between them, where everyone can feel love, cooperation, harmony, enjoyable and happiness through teacher cooperation in achieving a common goal. As Acker (1999) cited in Wahbi (2000).

\section{The difficulties facing English language teachers in career development}

16 respondents show the impact of the difficulties facing English language teachers in career development. It was a high average from the respondents. They said: English language teachers do not collaborate with each other in decision making.. English language teachers are incapable of evaluating students and curriculums. The lack of actual support for English language teachers The absence of teachers for English language training programs because they do not believe in it. English language teachers are incapable of connecting Professional competence and practicality. English language teachers are characterized by their professional and teaching excellent skills. The achievements of English language teachers are due to self confidence and job satisfaction. ignoring educational efficiency of the English language teacher, the renewal of their experience, and their relation to areas characterized by culture and education. Weakness of openness and taking advantage from other international experiences and achievements .Failure in adopting clear policies and incentive to provide any material and moral motivations for the English language teachers in the department .It is important to raise English language teachers efficiency through training courses and missions according to modern technology development, to enhance teacher styles and strategies of teaching. In order to achieve this aim and to plan for curriculum in the best ways through training program in appropriate place, teachers must be given a chance to be in contact native speakers .

\section{The difficulties facing English language teachers with the curriculum}

12 respondents show the impact of the difficulties facing English language teachers with the curriculum . their saying is that: English language teachers do not participate in criticism and curriculum development. Poor supervision of the curriculum, in terms of typographical errors, and the paper type and size of the book The curriculum is inconsistent with the educational revolution of this generation. There isn't any specific teaching methods which help develop the learning skills of students. The subjects are intensive and long. The subjects are hard and not suitable for students. Rigidity of the curriculum, where updates and improvements of the curriculum were not done. Time schedule of the English subject is limited and short. The aversion the English subject and the lack of motives for students There are mistakes of language or educational material in English subject.
All these problems appear because English language teachers do not participate in criticism and curriculum development. In addition to the fact that curriculum designers do not have enough knowledge about students' abilities, skills and point of strength and weakness of curriculum. It also shows students' motivation for learning English language .They recognized English as a language of the times and they can treat and contact with all people in the world to make motivates for students to learn and master English Language.

\section{The difficulties facing English language teachers in the work environment:}

18 respondents show the impact of the difficulties facing English language teachers with the work environment. It is very high average they said: English language teachers are incapable of using new methods of teaching. The educational skills of English language teachers is weak in teaching English subject. The English language curriculum is considered to be traditional. The amount of students in one lesson is very large. English language teachers give lectures to a large amount of students per week. English language teachers are capable of teaching other subjects. The weakness of instructive communicative skills between teachers and students. English language teachers are not appreciated in secondary schools. The technological tools used in educating are very limited. English language teachers are constantly changing in secondary schools. It is believed that changing English language teachers affect their performance, their motivation and love of work . Every teacher has his/her special techniques in teaching that arouse students' interest in learning. it also indicates that teachers ought to have good experiences, develop their abilities and create new techniques in the field of teaching and learning process.

\section{The difficulties facing English language teachers with students}

13 respondent more than half percent show the impact of the difficulties facing English language teachers with students. Their saying round these: English language teachers are unable to understand the behavior of students. Students reduce the importance of educational activities and events. The skills of students in English language is very weak. The educational background of English language in students is limited. There is no motivation for students to learn English language. Some of the students may have difficulties in learning English culture. The application of English language is limited within the time of the lecture.

All what is said by the respondents because of English language is limited within the time of lecture and due to the lack of workshops designed to improve English language among students. This shows the low level of teacher expertise in the field of psychology and his/her skills in teaching without regard to the importance of understanding the behavior of the students. 


\section{International Journal of Science and Research (IJSR) \\ ISSN (Online): 2319-7064}

Index Copernicus Value (2013): 6.14 | Impact Factor (2014): 5.611

\section{Results}

Based on the analysis of statistically obtained data in this study, the researcher has come to the following findings:

1) Most of the Sudanese English secondary school teachers of English suffer from great professional difficulties in all study domains.

2) There were clear difficulties facing Sudanese English secondary school teachers with the administration due to the boredom of routine management procedures within the organization.

3) There were difficulties facing Sudanese English secondary school teachers with career development due to ignoring educational efficiency of the English language teacher, the renewal of their experience, and their relation to areas characterized by culture and education.

4) There were also difficulties facing Sudanese English secondary school teachers with colleagues in the department due to poor communication among English language teachers with each other and with other colleagues.

5) There were clear difficulties facing Sudanese English secondary school teachers with work environment due to the fact that they are constantly changing.

6) There were difficulties facing in universities with students due to the limited use of English language which is only in the time of lesson.

\section{Recommendations}

\section{According to the above findings the researcher recommends the following:}

1) Teachers must get training courses which will free them from psychological stress and pressure.

2) English language teachers must receive a salary equivalent to the importance of their task, sufficient to place them in a position of equality with official employees.

3) Teachers must receive the moral recognition suitable to their responsibilities. They must have a good working environment, including the high technology and resources essential for good teaching, in addition to real protection in terms of occupational health and safety.

4) Teachers must receive in-service training and professional development in order to keep in touch with new teaching styles and strategies.

\section{References}

[1] Barqawi , F. (1995) The status of English language Teaching and Acquisition in private schools as compared to public schools in compulsory stage in West Bank, Master thesis. P. 18-20.
[2] Bonenfant de (2000), Enabling Teachers Enable Teachers.

[3] Braskamp, L. A., \& Ory, J. C. (1994). Assessing faculty work: Enhancing individual and instructional practice. San Francisco: Jossey-Bass.

[4] Brooks, L.B (2002). Elementary schools teachers' impression formation and referral decisions for children with behavior problems, DAI-B62/08, P.3794, 0-493$362 / 2-6$

[5] .Craft, A (1997). Identity and Creativity: Educating Teachers for Post modernism, Teacher Development, Vol1, No1.

[6] Cushing, A.E. (2002). Teacher personality, Stress, and difficult students: An Adlerin perspective. DAI-A 62/10. P.3302, 0-493-42282-x.

[7] De Bonenfant, J.L (2001) Exploring the difficulties of teaching English as a second language (TESOL), DAI 61/10, P. 3971, 0-599-97483-4.

[8] Hargreaves, A- \& Tucker, E (1991) Teaching and Psychology: exploring the feelings of teaching, Teacher and Teacher Education, 7, PP. 491-502.

[9] Jefferson, G.L (2001). An evaluation of the generalized effects of truing teachers of young children to use functional assessment in combination with behavioral consultation to remedial problematic classroom behaviors, DAI-B 62/06, P.2948, 0-49.-29506-2

[10] Jossy-Bass (2000) Educational leadership Awiley Company. www.Jossybass.Com.

[11] Keyurawong. S (2002), English language instruction in universities is about to get an overhaul. Thai TESOL Focus, 15(1), 10.

[12] Lantolf, C. (2000), Socio cultural theory and second language learning: Recent advances, Oxford University Press J. (Ed.).

[13] Me-Schools, (2002). Motivation - fundamental Worries. New letters.

[14] Mohammad Salem (2011), The Classroom Problems Faced Teachers at the Solutions Kamla, P. 37-48.

[15] Ntiforo, M.L.E (2001). Mentoring and New Elementary School Teachers: Problems and Progress, DAI - A 62/04, P. 1316, 0-493-22488-2.

[16] Reys, R. E. 2001. Curricular controversy in the math wars: A battle without winners. Phi Delta Kappan 83(3)(November):255-58.

[17]Richard B. Baldauf Jr. and Karen Moni (2006), LEARNER-CENTEREDNESS IN TEACHING ENGLISH AS A FOREIGN LANGUAGE Feachers' Voices", Learner Centeredness in Teaching English as a Foreign Language, Paper Presented at 26 Thai TESOL International Conference, Chiang Mai, Thailand, 19-21 January 2006, 1-9. (C) $2006 \mathrm{~K}$. Nonkukhetkhong.

[18]Richard H et al, and other, Gorden A Peheca Vander Bogert (1996) Marking sense As a school leader.

[19] Richards, J., Platt, J., \& Platt, H. (1992). Dictionary of language teaching and applied linguistics (2nd ed.). Essex, England: Longman. 


\section{International Journal of Science and Research (IJSR) \\ ISSN (Online): 2319-7064}

Index Copernicus Value (2013): 6.14 | Impact Factor (2014): 5.611

\section{(Appendix)}

An Interview with some experts and directors of the

English Language In Secondary Schools

\section{Dear colleague,}

This is an interview for academic paper entitled "secondary schools English teachers' problems and their impact on his performance in sudan" According to your own point of view, I would be very grateful if you might help me in answering these questions of this interview. Please fill the first part ( personal information and then answer the questions), bear in mind that your answer will be used only for academic purpose.

\section{Personal information:}

Name :( optional)

Years of experience teaching English. age $\operatorname{sex}$

\section{The questions:}

1- Based on your interaction with English teachers, what are their main problems with the administration that has effective roles in students performance?

2- What are the expected environmental problems that reduce English teachers good performance?

3- Are there difficulties facing English language teachers with the curriculum?

4-Are there difficulties facing English language teacher with his students.

Thank you for your participation in answering the questions of the interview. Dr.E.E.Adam . the researcher 